\title{
History, Agency, Power, and Linked Fate*
}

\author{
Reuel Rogers ${ }^{\ddagger} J a e$ Yeon $\mathrm{Kim}^{\S}$
}

February 5, 2021

\begin{abstract}
Racial linked fate, the concept introduced by Dawson (1994) almost three decades ago, reoriented the study of racism and mass political behavior in the U.S. The scholarship traditionally had focused largely on the racial psychology of whites, how racism seeps into their political views and actions. Dawson proposed the black utility heuristic theory and linked fate, its associated measure, as an empirical framework to investigate the political behavior of blacks, the racial minority group most harmed by racism. Since then, linked fate has become an almost ubiquitous variable of interest in the research on minority group dynamics in American politics. Yet the research program around linked fate is due for some extension. We argue that subsequent studies largely gloss over the fact that the black utility heuristic theory, underlying the linked fate concept, is historically and socially conditional. We call for bringing elite level agency back into the literature to clarify the macro- and meso-level conditions under which shared racial status translates into linked fate at the individual level. Elite actions are critical to understanding linked fate as a contingent outcome shaped by group historical processes and social practices. We conclude that greater inquiry into these dynamics is not only warranted, but also has broad implications for the research on racial and ethnic politics. It requires rethinking the scope of the evidence and methods researchers utilize to study the politics of racially marginalized groups.
\end{abstract}

Keywords: Linked fate, group consciousness, racial and ethnic politics

\footnotetext{
${ }^{*}$ Both authors contributed equally to this article.

$\dagger$ All replication code is available at https://github.com/jaeyk/linked_fate_review

${ }^{\ddagger}$ Corresponding author. Associate Professor, Department of Political Science, Northwestern University, 601 University Place, Evanston, IL 60208, USA r-rogers@northwestern.edu

$\S \mathrm{PhD}$ Candidate, Department of Political Science, University of California, Berkeley, 210 Barrows Hall 1950, Berkeley, CA 94720, USA jaeyeonkim@berkeley.edu
} 


\section{Dawson's Unfinished Revolution}

Linked fate has become an almost ubiquitous variable of interest in scholarship on racial minority politics. Ever since Michael Dawson elaborated the concept and documented its far-reaching effects among blacks in his seminal study Behind the Mule (1994), it has risen to canonical status. Widely treated as a shorthand measure of racial solidarity, it is now the leading workhorse for understanding political groupness in non-white minority populations. The concept reoriented the study of racism and mass political behavior in the U.S. The scholarship traditionally had focused largely on the racial psychology of whites. It yielded a voluminous literature debating whether and how "the racist virus in the American bloodstream" infects whites' hearts, their minds, and ultimately their political behavior (e.g., Schuman, Steeh, Bobo, et al. 1985; Kinder, Sanders, and Sanders 1996; Sidanius, Pratto, and Bobo 1996; Sniderman and Piazza 1993). ${ }^{1}$ Proceeding instead from the premise that racism is not simply psychological, but also systemic and deep in the bones of American politics, Dawson's linked fate turned the empirical focus to those most harmed by the so-called virus. It foregrounded how blacks, and presumably other marginalized minorities, act politically to resist racism and pursue their interests in spite of it. The concept centered non-whites, focused on their agency, and shifted attention to relational power dynamics in America's racially stratified democracy. This amounted to nothing less than the start of an epistemological revolution in the study of race, ethnicity, and political behavior.

Yet as linked fate has gained broad currency, the research program around it has not quite matched the original scope of the concept. To survey how the linked fate literature has evolved, we turned to Google Scholar to inventory publications related to the concept. ${ }^{2}$ We used two search queries: (1) "linked fate" + "dawson" and (2) "linked fate" + "group consciousness" + "solidarity." We culled the initial 103 results for each query, sorted by

1. See Bobo and Charles (2009) for an overview of the literature. We borrow the quote from the same essay.

2. We conducted the search on May 21, 2019. We avoided collecting data on books, book chapters, and book reviews since they often replicate what individual research papers report. 
relevance, removed duplicates, and excluded non-empirical research in the data. The resulting sample $(\mathrm{N}=89)$ is not an exhaustive list of published articles on linked fate; rather, it is a coarse but meaningful indicator of how the scholarship on linked fate has developed.

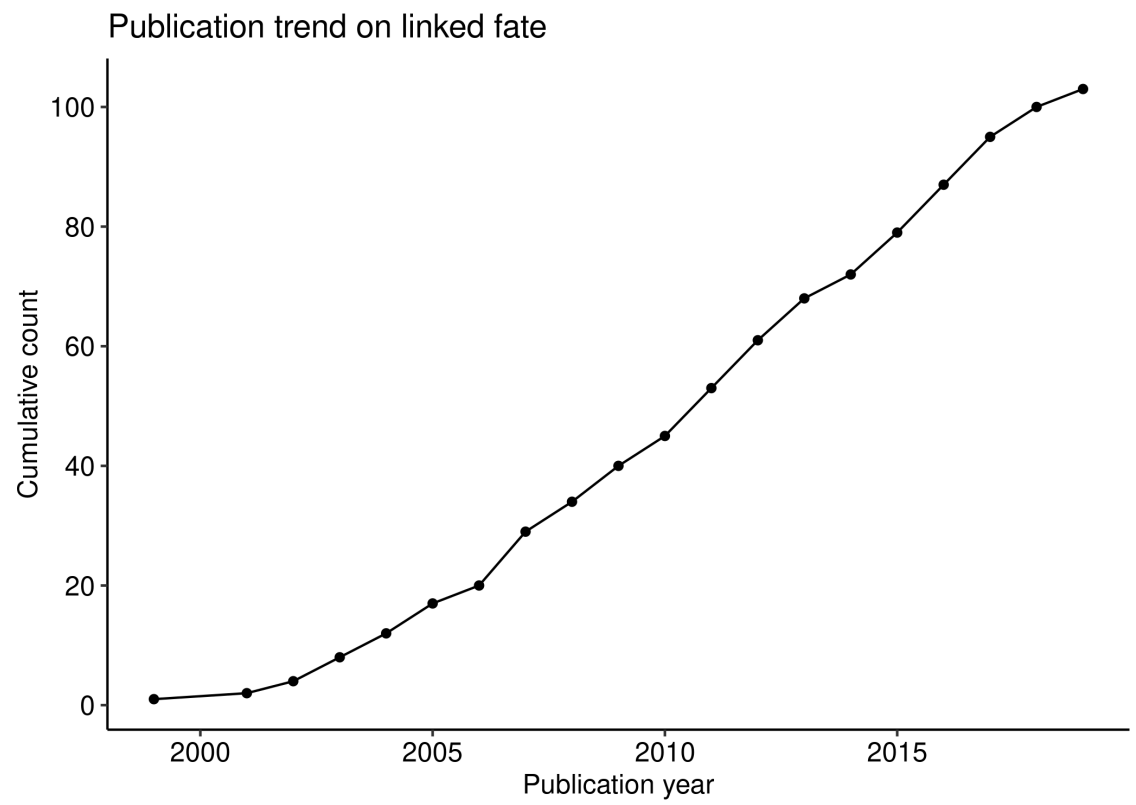

Figure 1: Publication trend on linked fate

The most notable pattern in the data is the increasing diversity of the research subjects - the populations researchers have targeted to investigate the concept. Not surprisingly, articles on African American linked fate comprise the majority (50\%) of all the publications captured by our search. But published research on other target groups has picked up pace in recent years. Figure A.1 in Online Appendix A shows that articles on Latinos surpassed those on African Americans in 2015. Besides, papers on a range of other groups-Asian Americans, black immigrants, whites, American Indians, women, transgender groups, Muslims, and even ethnic groups in Eastern Europe - have proliferated. This overall diversifying trend in the research literature on linked fate tracks with the changing racial demographics of the U.S. Over the past few decades, Latinxs have become the second largest racial group after whites (Colby and Ortman 2015), and Asian Americans currently rank as the fastest growing minority population (Barringer, Gardner, and Levin 1993). Linked fate studies of these two 
populations, comparisons between them, and analyses of the various nationality groups that comprise them have all increased. As the country's racial demography has diversified then, so too has the range of groups analyzed in the linked fate scholarship.

Theoretical and methodological approaches to studying the concept, however, have been less diverse. Behavioral studies are overwhelmingly predominant. This kind of research tends to prioritize methods that pinpoint patterns in mass-level public opinion. Consequently, survey data are prevalent (see Figure A.2 in Online Appendix A). The empirical contributions generated by survey-based studies have been substantial. They have provided a snapshot of the distribution of individual-level linked fate perceptions across various racial and ethnic groups; how linked fate correlates with other political variables of interest (e.g., political participation, policy preferences, perceptions of discrimination, etc.) in these populations; and how it covaries with standard socioeconomic characteristics (e.g., education, income, gender, national origin, generation, etc.). Methodological and theoretical controversies have been relatively muted, confined mostly to measurement inconsistencies or occasional debates about whether linked fate is an appropriate surrogate for other, more complex, forms of group solidarity (i.e., group consciousness) (e.g., Chong and Rogers 2005; Masuoka 2006; Chong and Kim 2006; Philpot and Walton Jr 2007; White 2007; Junn and Masuoka 2008; Sanchez 2008; McConnaughy et al. 2010; Sanchez and Masuoka 2010; Austin, Middleton, and Yon 2012; Watts Smith 2013; Hurwitz, Peffley, and Mondak 2015; Gay, Hochschild, and White 2016; Vargas, Sanchez, and Valdez 2017; Lu and Jones 2019).

But the heavy reliance on survey-based behavioral approaches can obscure key elements of the original theory underlying the linked fate concept, Dawson's black utility heuristic. Linked fate perceptions are only a part of this larger theoretical framework - and they are the most micro-level, individualistic dimension of it at that. The black utility heuristic theory extends beyond the micro-level perceptions and calculations of individuals in the black mass public. It specifies dynamics operating at the macro-, meso-, and micro-levels that together have led to the emergence of this form of racial group solidarity among blacks. It 
actually begins at the marco-level with the brutal material conditions and historical legacies that have cemented blacks' subordinate position in the country's racial hierarchy: slavery, the authoritarian Jim Crow regime, residential segregation, anti-Black violence, economic precarity. It then turns crucially to meso-level dynamics involving elites, the strategic choices they make, the messages they convey about the value of racial solidarity, and the social structure of the groups they lead. Finally, the theory arrives at the micro level when racial group identification in the form of linked fate takes root, acquires psychological significance, and guides political decision-making among individual blacks.

When linked fate registers such cognitive utility at the individual level, this is actually the last element in a "slow-moving process" (Pierson 2003). It is the final step in "the identity-to-politics link" (Lee 2008). Many behavioral studies of linked fate focus only on this last step. They bypass or give rather cursory attention to the macro- and especially the meso-level components of Dawson's original theory. Consequently, the behavioral research as a whole still has ample room to generate comprehensive and conceptually valid explanations of linked fate in minority populations (Gay, Hochschild, and White 2016; McClain et al. 2009).

In what follows, we propose a way forward for advancing the research program around linked fate and completing Dawson's unfinished revolution. First, we recover the theoretical foundation underlying the concept. We call for bringing elite-level agency and group-level social practices back into the literature to clarify the macro and meso conditions under which shared marginalized racial status translates into individual-level racial group consciousness. We theorize that elite actions are especially critical for understanding linked fate as a contingent outcome shaped by group historical processes and social dynamics. We then recommend augmenting the empirical strategies researchers deploy to study linked fate and other forms of group solidarity. We argue for multiple streams of evidence and methods that not only center these marginalized populations, but also fully capture their lived experiences. This diverse, integrative approach widens the scope of the theoretical discussions and expands the methodological toolbox for studying the politics of race and ethnicity in the U.S. 


\section{Bringing History and Agency Back in Linked Fate Research}

We begin with a brief primer on linked fate and the underlying black utility heuristic theory. Despite the ubiquity of the linked fate concept in the research on racial and ethnic politics, Dawson originally developed it to understand patterns in black politics - particularly the welldocumented high levels of political uniformity in the group. A long line of studies dating back decades has attributed distinctive tendencies in black politics, including this overwhelming political unanimity, to the salience of racial group identification in the population (e.g., Verba and Nie 1972; Shingles 1981; Pinderhughes 1987). As Dawson showed in Behind the Mule, political homogeneity persists among African Americans in large part because linked fate perceptions are so widespread in the group. He concludes that linked fate is a key driver of "solidarity politics" among African Americans. ${ }^{3}$. It is the linchpin to blacks' unity in the political arena, most apparent in their collective efforts to challenge white supremacy and improve their standing.

Dawson defines linked fate as an identity construct that reflects "the degree to which African Americans believe their own self-interests are linked to the interests of the race" (1994, 77). Blacks who evince linked fate are convinced that their individual life chances are tethered to the collective fortunes of their racial group. Prior to Dawson, other researchers had developed similar ideas, such as interdependence and common fate, to explain politicized group consciousness in blacks and other social groups (e.g., Conover 1984, 1988; Gurin, Hatchett, and Jackson 1989). But he was the first to hypothesize a direct link between individual self-interest and racial group interests in blacks' political decision-making.

This perceived connection between individual and group outcomes is what prompts African Americans to substitute the collective racial good for their own personal interests. Dawson argues that blacks use the group's absolute and relative status, usually vis-a-vis whites,

3. We borrow the term "solidarity politics" from Shelby (2005), quoted in White and Laird (2020). 
as a proxy for their individual utility calculations (1994, 10-11). They tend to make this substitution in low information situations when the group implications of a political decision might be more accessible and easier to discern than their own distinct personal utilities. Linked fate operates as a heuristic or informational shortcut in these instances (e.g., Lupia 1994; Popkin 1993). By focusing on interests and information, Dawson's conceptualization of linked fate emphasizes the rational, rather than the affective dimensions of group solidarity. This linked fate is not just a feeling; it is also a way of knowing.

The black utility heuristic theory is the skeleton key for studying linked fate. It specifies the conditions under which linked fate should wax and wane in the black population. It provides the basis for predicting precisely when the collective good of the racial group might supersede individual interests in African Americans' political calculations - and alternatively when it might take a cognitive back seat (61). This is how Dawson stipulates the basic logic of the theory: "[A]s long as African-Americans' life chances are powerfully shaped by race, it is efficient for individual African Americans to use their perceptions of the interests of African Americans as a group as a proxy for their own interests" (61). The theory thus draws a causal chain from the overarching conditions faced by the racial group to individual-level perceptions of linked fate (i.e., group solidarity) in black politics.

Metaphorically, linked fate might be the most exciting part near the end of a 2-hour movie on the politics of racial group solidarity. Paying attention to all the preceding developments is crucial for understanding how characters developed and the plot unspooled. Yet behavioral studies of linked fate, operationalized simply as an individual-level dispositional variable, often skip over the early parts of the plot. This is especially evident in analyses extending linked fate by analogy to minority groups other than African Americans. These studies typically have trained their focus on just a couple discrete explanatory variables.

Many of them investigate the causal impact of discrimination. ${ }^{4}$ Experiences or perceptions of discrimination are hypothesized to foster or strengthen linked fate. Researchers have tested

4. Researchers also routinely treat perceptions or experiences of discrimination as an indicator of other forms of racial identity like group consciousness. 
this hypothesis with a range of groups, including Latinxs, Asian Americans, Muslims, and women as well as African Americans (Lien, Margaret Conway, and Wong 2003; Masuoka 2006; Junn and Masuoka 2008; Barreto et al. 2009; Barreto and Bozonelos 2009; McClain et al. 2009; Sanchez and Masuoka 2010; Gay, Hochschild, and White 2016; Sanchez and Vargas 2016; Stout, Kretschmer, and Ruppanner 2017; Verkuyten 2017). Most of the studies rely on surveys and statistical models to test the argument. They routinely operationalize the linked fate dependent variable with a pair of survey items that more or less replicate the wording of the measures in Dawson's original work: [what happens to [your group] in this country will have something to do with what happens in your life]. They also sometimes supplement the standard linked fate measures with items tapping more complex forms of racial solidarity like group consciousness (e.g., Masuoka 2006; Sanchez and Vargas 2016)

The findings have been decidedly mixed. ${ }^{5}$ For example, Masuoka (2006) concludes that racial discrimination predicts group consciousness among both Asian Americans and Latinos. ${ }^{6}$ Sanchez and Masuoka (2010, 525-526), however, find that, among a range of potential explanatory variables, it is "Latinos getting ahead," not "discrimination experience," that yields a statistically measurable relationship with linked fate in a sample of Latino survey respondents. In fact, the effect size of "Latinos getting ahead" is much larger than that of "discrimination experience." Still, a more recent analysis based on 2016 data reveals a statistically significant and positive association between Latino linked fate and discrimination (Sanchez, Masuoka, and Abrams 2019). The evidential inconsistency is not limited to the research on non-black racial minorities either. Gay, Hochschild, and White (2016, 135), for instance, show that "perceptions of discrimination" are weakly related to linked fate among all four major racial groups - whites, Latinos, Asian Americans, and African Americans (see also Gay 2004; Chong and Kim 2006).

5. See Jardina and Piston (2019) for a recent summary of the mixed results from studies of linked fate among Asian American and Latino populations.

6. Masuoka tests two different racial discrimination measures: personal experiences with discrimination and perceptions of discrimination. The former is correlated with racial group consciousness among Asian Americans, whereas the latter has a stronger statistical relationship among Latinxs. 
There are two possible explanations for these mixed findings. First, the issue could be purely methodological. Perhaps the sampling in many of the extant studies is biased and the models are mis-specified. If this is the case, researchers can course correct by collecting higher-quality data and applying more rigorous methods. For example, scholars can define a discrete "linked fate" treatment-a constitutive, manipulable racial feature thought to foster this form of solidarity-and then design an experiment to estimate its effect. ${ }^{7}$ The other possibility is theoretical. Problems stemming from theory pose a more fundamental challenge to this body of research. They cannot be rectified simply by leveraging better data or more sophisticated analytic techniques. Rather, they call for clarifying the scope and dimensions of the theory underlying linked fate. We believe that careful attention to the components of the theory can help to identify what approaches and kinds of evidence could generate reliable insights on how the construct develops and operates among racial minorities.

Black utility heuristic theory takes both the historical and social origins of racial group solidarity seriously (Dawson 1994, 48-60). These macro- and meso-level components are not mere background information; they are predicates for the basic political logic of Dawson's linked fate. "Politics" he explains, "is much more than simply the behavior of individuals or the sum of these individual actions ... one clearly needs to pay more attention to the boundaries between society and the individual, with the group as the intermediary phenomenon" (13). If these macro- and meso-contextual factors were not specified, the black utility heuristic would be a rather narrow theory about the micro-level cognitive processing of racial cues (i.e., perceptions of discrimination, feelings of ingroup closeness, etc.). The fully elaborated theory actually lays out a constellation of upstream factors that structure how blacks-and presumably other racial minorities-harness group solidarity to assert their political agency.

So besides utilizing statistical models to understand the relationship between linked fate and other individual-level variables, Dawson traces the antecedents of linked fate to a set

7. See Sen and Wasow (2016) on applying an experimental approach to the study of race. 
of macro- and meso-level conditions in blacks' lived and historical experiences (Figure 2). When he laid out and proceeded to validate the theory in the 1994 study, he did not attempt to isolate the effects of discrete causal variables. He did not estimate, for instance, the causal impact of discrimination on perceptions of linked fate. He certainly suggests that "individual experiences with discrimination" can motivate and sustain linked fate (63). But the psychological pivot from perceptions of discrimination to this politicized form of racial group solidarity is neither reflexive nor ineluctable. Rather, under the black utility heuristic theory, an individual's evolution from the experience of discrimination to linked fate is best understood as contingent.

\section{Black Utility Heuristic Theory}

Macro (t1) Material conditions and historical legacies

Meso (t2) Elites' messaging and group social dynamics
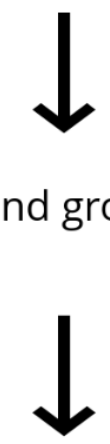

Micro (t3) Racial group identification (linked fate)

Figure 2: A schematic causal diagram of black utility heuristic theory

As Figure 2 illustrates, Dawson's theory treats the formation of linked fate as conditional, context-dependent, and elite-driven. The theory is configurational. Linked fate is the result of a complex combination of "racializing" and "consciousness-raising" phenomena, including but not limited to discrimination. Exposure to discrimination alone does not necessarily give rise to group solidarity. On the contrary, such hardship could lead to an emphasis on assimilation, a rejection of racial group ties, and a reliance solely on individual effort to pursue 
social mobility (Chong 2000). Blacks historically have debated these alternative possibilities when considering the advisability of collectivist versus individualist strategies for overcoming racism. $^{8}$

Discrimination is simply one stick in the bundle that constitute the necessary conditions for the emergence of a collectivist mindset like linked fate in individuals at the mass level. It has to be configured with other forces to foster racial group solidarity. Yet the commonly tested hypothesis drawing a causal arrow from discrimination to linked fate ignores these other factors, often relegating them to a black box of unspecified assumptions. Although there are notable exceptions, behavioral studies based on this overly simplified version of the black utility heuristic theory tend to gloss over the other forces that lead to the formation of individual-level linked fate. ${ }^{9}$

The factors that often get empirical short shrift are the macro- and meso-level historical processes, social practices, and elite dynamics posited in the theory. The inequalities that marginalize racial minority groups do not emerge ex nihilo. Most researchers agree that they are, at least in part, the historical legacies of racial injustices ( $t_{1}$ in Figure 2$)$. In the case of African Americans, systemic conditions like slavery, Jim Crow, and segregation have made marginalization not just an individual challenge, but a communal predicament faced by the entire group Dawson (1994, 48-57). Beyond battering minority groups into a subordinate structural position, these conditions prompt ingroup elites to mobilize non-elites around their shared racial identity and (mis)fortunes. Elites take the lead in generating the political agency necessary for mounting resistance ( $t_{2}$ in Figure 2$)$. They give racial solidarity (i.e., linked fate) political meaning and purpose (Hogg and Reid 2006; Huddy 2013). Social practices, in turn, can amplify and sustain this sense of racial solidarity within groups $\left(t_{2}\right.$ in Figure 2$)$. Social dynamics influence how much traction linked fate and other politically consequential

8. These alternatives registered famously in the ideologies advanced by W. E. B. Du Bois and Booker T. Washington respectively (Shelby 2005; Jagmohan 2015).

9. White, Laird, and Allen (2014) is one admirable exception (also White and Laird 2020). It demonstrates that linked fate among African Americans is conditional on racialized social pressure and internalized beliefs in group solidarity. 
forms of racial solidarity attain at the individual level.

First, elites play a pivotal role in the political learning process (Zaller 1992). Minority group leaders help individuals make sense of the macro-level conditions they face in common with their racial peers; they identify the immediate and downdraft consequences of these conditions for the group. They interpret what these shared racial experiences mean politically, advocate strategies for addressing them, and purvey these messages to group members. They are uniquely positioned to play this role because they can use their proverbial megaphones to sound the alarm and galvanize non-elites. In short, elites set the agenda for the group by elevating and targeting issues for political action (Dawson 2001; Tate 2010). How elites prioritize issues and set mobilization goals is consequential for how linked fate forms. As Cohen's seminal study demonstrated, this agenda-setting process delineates the boundaries of groupness - or as she put it in the African American case, the "boundaries of Blackness" (1999).

Besides clarifying the strategic plans of elites, the process reveals which issues or positions they deem congruent with "racial group" interests, and whom they consider core versus peripheral members of the group. African American leaders, for example, are key influencers of partisan preferences in the black population. When figures like Barack Obama or Jesse Jackson tout support for the Democratic Party as good for the racial group, they translate this partisan choice into a normative one for African Americans. This elite-level exhortation transforms identifying with Democrats into an act of racial solidarity. It is something that individual African-American voters ought to do in the interest of blacks as a whole; making another choice, like supporting a Republican candidate at the polls, is out of racial bounds. This is how elites take the lead in crystallizing political norms of solidarity in a racial group (Cohen 1999; White, Laird, and Allen 2014).

Second, ingroup elites typically convey these agenda-setting lessons and signals through a network of indigenous institutions. In his theorization of black racial solidarity and elaboration of the utility heuristic, Dawson $(2001,1994)$ assigned crucial significance to just such a network 
in the African-American population, dubbing it the black counterpublic. The counterpublic emerged just after the Civil War and expanded during the Jim Crow era when extreme segregation barred blacks from participation in white civil society. This network of all-black institutions historically has included civil rights organizations, trade unions, social clubs, colleges, and principally black churches. It also encompasses indigenous media outlets and informal public spaces, such as barbershops and beauty salons (Harris-Perry 2004).

Elite messages are not simply disseminated via this network. They are also debated, vetted, and synthesized. They are then amplified and reinforced via social connections among rank-and-file blacks, which are especially pronounced as a result of their high levels of residential segregation (White and Laird 2020; Rogers 2018). A particular set of messages gains wide currency and ultimately emerges as a collective vision of black politics, akin to a unifying political agenda (Dawson 2001). As Dawson explains, "Black institutions and social networks ... serve to limit the reduction of black political homogeneity." He concludes that "as ties with the black community and community institutions became progressively weaker, one would expect to see a decline in group consciousness in this stratum" (59). This counterpublic network is the key crucible, then, for mobilizing and sustaining group solidarity in black politics, including perceptions of linked fate. Presumably, indigenous networks might operate to similar political effect in other racial minority groups. It depends on how well developed these institutional networks are and how socially interconnected group members are. Not all racial minority populations boast the extensive institutional infrastructure and thick social bonds that prevail among blacks.

A substantial portion of the research extending linked fate from African Americans to other racial minority groups is based, however, on a kind of analogical reasoning that elides distinctions in these consequential historical processes, social practices, and elite dynamics. The reasoning is informed by two assumptions: that (1) one particular set of features (i.e., discrimination) is more significant than others; and that (2) cases of interest are highly comparable per those selected features. When researchers focus exclusively on exposure to 
discrimination as the key causal mechanism underlying linked fate, all racial minority groups might seem like commensurate cases. After all, most of them inevitably encounter some degree of discrimination in the U.S.

Yet this version of the black utility heuristic theory may be too deterministic. It does not necessarily square with the experiences of non-black minority groups. Their marginalized racial status has not always led to collective mobilization or coalition building with racial peers. Asian Americans, for instance, remained divided along national origin lines until a new generation of activists mobilized these groups in the 1960s and 1970s (Espiritu 1993; Okamoto 2014). Likewise race-based political solidarity among Latinos has emerged only in the past half century (Padilla 1985; Mora 2014; J. Y. Kim 2020a). If oversimplification leads to myopic determinism, paying close attention to distinct historical processes and elite strategic behavior across these groups may be the solution. It could help to clarify the contingent nature of the collective mobilization and coalition building that ultimately produce linked fate.

For example, J. Y. Kim (2020b) shows that despite their shared racial status as "Orientals," Chinese ethnics across the United States and the Canadian border did not all pursue a race-based coalition strategy to fight gentrification and call for affordable housing in their neighborhoods during the 1960s and 1970s. Asian race-based coalitions appeared in San Francisco and Seattle, but not in Vancouver, where a cross-racial coalition was forged between the Chinese and southern and eastern Europeans. The differences across these cases emerged because ethnic community organizers in each city were strategic. They chose their allies based on (1) the size and (2) the strength of their social relations with each prospective partner group. Weighing these factors often entails a trade-off: larger partner groups are useful for asserting political power; but they also may inflate coordination costs depending on their previous relationship with the group making the assessment.

By the 1960s and 1970s when the Chinese needed to choose coalition partners, the candidate pool had already been determined by historical legacies. Past immigration and 
segregation policies set the course for the demographic and residential patterns that informed community organizers' strategic calculations. The Chinese in San Francisco and Seattle allied with other Asian ethnic populations because these groups were large and familiar to them as friends and neighbors. In contrast, their counterparts in Vancouver, using the same strategic calculus, surmised that southern and eastern Europeans would be their ideal coalition partners.

This brief historical comparison shows that distinct racial predicaments and policy environments have shaped solidarity politics in these populations. Some researchers rightly have called for more specificity in empirical accounts of the forms of racial marginalization that saddle different minority groups (Masuoka and Junn 2013; Rosenbloom and Way 2004; C. J. Kim 1999). Racial marginalization is not monolithic across groups. Nor is linked fate or any form of racial solidarity a one-size-fits-all construct. Meso-level investigations into historical processes, elite behavior, and ingroup social practices can illuminate variations in both racial marginalization and solidarity building across minority populations. Careful attention to these details can help to clarify when and where discrimination might or might not activate linked fate. The practice of analogizing across groups of color solely on the basis of their vulnerability to discrimination misses these critical distinctions and contingencies. ${ }^{10}$

Analogical reasoning has limits even for understanding how racial solidarity has evolved in black politics, especially when we consider internal dynamics and status differences in the population. Although all blacks are vulnerable to racial discrimination, the interests of all blacks are not necessarily treated equally in the elite-driven process that gives rise to solidarity in black politics. In her study of African Americans' initially halting political response to the AIDS epidemic, for example, Cohen (1999) concludes that black elites center specific concerns as integral to the collective interests of the group while marginalizing other issues as incompatible or even antithetical to the black political agenda. In short, black

10. Sexton calls this practice of wholesale analogizing across minority groups "people-of-color-blindness." It is "a form of color blindness inherent in the concept of 'people of color' to the extent that it misunderstands the specificity of anti-Blackness and presumes or insists upon the monolithic character of victimization under [w] hite supremacy" (quoted in C. J. Kim 2018, 225) 
leaders have sought to mobilize racial solidarity for some ingroup interests while inhibiting it for others.

Pointing to a similar process, Rogers (2006) observes that coalition building between African Americans and Afro-Caribbeans has been fitful and occasionally contentious despite their shared racial status as blacks. Elites in both groups sometimes have instrumental motivations that lead them to accentuate their distinct competing ethnic interests rather than promote racial solidarity, particularly in battles for electoral office. During these conflicts, African-American elites at times have asserted greater authority to define the agenda for black solidarity politics than their Afro-Caribbean counterparts.

These examples from black and Asian American politics illustrate a key point: racial solidarity may be unifying and yet not necessarily equalizing, encompassing and still not fully inclusionary. The analogical reasoning underlying some behavioral studies of linked fate misses these caveats. But they are crucial to understanding how racial solidarity evolves and then develops at the individual level. The shared racial group interests that motivate solidarity politics should not be taken for granted or treated priori as essential properties of racialized minority populations. Group interests are constructed through agenda-setting and mobilization networks. Racial solidarity in minority group politics is not simply a mutual feeling or a shared psychological reaction to discrimination. It is a process shaped by historical contingencies, indigenous social practices, and the agency of ingroup elites.

\section{Evidence, Methods, and Racial and Ethnic Politics}

If we study linked fate as a process, the dynamics look like a kind of two-step communication flow (Lazarsfeld, Berelson, and Gaudet 1944; Katz 1957; Zaller 1992; Lenz 2013). There are two actors, elites and masses, and they move in sequences. Elites dominate the upstream stage. They are faster than the masses in acquiring new political information, and more sophisticated in interpreting it. In addition, they have greater access to resources and networks to spread 
their political knowledge and leverage it to mobilize group members. The masses drive the downstream stage. They receive messages from elites and decide whether to accept them or not depending on their individual predispositions and circumstances. This delineation of the roles is empirically observable, but can be unclear during social movements when the boundary between elites and masses is blurred (Lee 2002).

To the extent that black utility heuristic theory encompasses processes unfolding at both levels, testing linked fate requires an integrative research program that targets elites as well as the masses. Without knowing what ethnic elites say and do, it is hard to create valid survey instruments and experimental manipulations to investigate how the concept operates in political behavior at the mass level. Bringing the agency of ethnic elites into the purview of research programs on linked fate would help improve the behavioral scholarship by sharpening not only observable implications but also elements of research design like measurement.

Incorporating elite-level dynamics into the study of linked fate requires rethinking what data are worth collecting and analyzing. Historical data on ethnic elites' political discourse exist in the form of archival documents, literary texts, and oral history. Sociologists, historians, and ethnic studies scholars have utilized these data sources to understand the racialized lived experiences of ethnic minorities and how those same experiences influence mobilization and coalition building among these groups. Admittedly, using these resources could be challenging for quantitatively-oriented political scientists, most of whom have been trained to work with tabular data (e.g., Excel spreadsheets or comma-separated values files). Even simple quantification, like counting words from these un- or semi-structured data sources, could be quite complicated and not as intuitive as it might appear at first blush.

But recent technical and infrastructural advances bode well for addressing these challenges. Computational tools and techniques have lowered the cost of analyzing these texts at scale. Data vendors, such as ProQuest, have digitized millions of ethnic newspapers and magazines published in the U.S. and made them accessible to researchers. A recent study (J. Y. Kim 2021) demonstrates that applying computational methods to the large volume of African American 
and Asian American ethnic newspapers can provide new insights into the commonalities and similarities in the political issues these groups have confronted.

Researchers interested in linked fate and other phenomena in racial and ethnic politics also should make greater use of field-focused methods like interviews and participant observation. For political scientists who study comparative politics, fieldwork is foundational and frequently integrated with other methods (Brady and Collier 2010; Seawright 2016). In contrast, behaviorists in the American politics subfield largely neglect fieldwork, seemingly undervaluing the knowledge to be gained from such methods. Americanists instead emphasize proficiency in a specific theoretical and methodological approach suitable for the study of a particular aspect of American politics. For instance, public opinion researchers rely heavily on survey techniques and large representative samples to measure concepts in the existing literature. This method limits them to close-ended questions designed to tap into ideas deduced from established theories. The formulation of these questions and the corresponding ideas, however, may be quite removed from the everyday political experiences of some Americans.

One epistemological virtue of in-depth field interviews is that they engage respondents in the context of their lives. Field research can be used to interpret and evaluate frameworks, often with interview questions based on the same existing literature that informs survey instrumentation. But in-depth interviews are more instructive than surveys when interviewee accounts do not align with expectations stemming from the extant scholarship (Rosenthal 2020). In these instances, researchers can observe patterns in what interviewees say not only to critique the literature, but also to innovate or deepen theory and conceptualization.

A field research approach that engages people in the context of their lived experiences has other benefits for studying concepts like linked fate in racial minority populations. Focus groups and participant observation, for example, enable researchers to observe social practices (i.e., racial peer pressure) that bolster group solidarity. These methods also offer a glimpse of how elite messages about group interests are translated to the everyday talk of non-elites on the ground (Harris-Perry 2004). This kind of evidence can serve as a transcript of ideas 
and idioms that could be incorporated into survey instrumentation. Some of these social dynamics certainly can be approximated with experimental treatments or uncovered with open-ended questions on surveys. But these techniques are hardly perfect substitutes for the lived experiences of these populations.

The more common specialized approaches in the American politics subfield are especially hard to justify when researching the politics of marginalized groups because they are so detached from politics on the ground. Many key questions in standard public opinion datasets, for instance, implicitly assume white voters as their main targets. The questions are often designed with whites in mind, based on how they would be expected to construe each item. Take political knowledge for example. A series of questions about the workings of U.S. mainstream institutions could be a useful measure for gauging the depth of white voters' knowledge of American politics. But for groups that historically have experienced little democratic responsiveness or have been oppressed by these very institutions, such questions may be less illuminating or valid.

As recent studies (Cohen and Luttig 2020; Weaver, Prowse, and Piston 2019) have demonstrated, members of marginalized minority groups often have much deeper knowledge of how the U.S. government has worked against them rather than for them. As a result of their power to control and regulate people, some government institutions are also more visible to these groups than they are to whites (Rosenthal 2020; Michener, SoRelle, and Thurston 2020). Minorities too often see the most menacing face of these institutions and experience the most broken parts of American democracy. These insights frequently come from field research that includes in-depth conversations and interviews with individuals about their actual lived experiences and encounters with government.

In general, racial and ethnic politics scholarship should not incorporate or replicate de rigeur theories and measures that initially were designed in the American politics subfield to study the political behavior of the dominant group (i.e., whites)-at least not without critical reflection. Instead the research should foreground ideas and frameworks that capture the lived 
experiences of subjugated, marginalized minority populations. Besides understanding how mainstream theories of American politics and various quantitative and qualitative methods apply to these minorities, racial and ethnic politics scholars also need to learn and emphasize the history, discourse, and cultures of the communities they are committed to studying. One of the key objectives of racial and ethnic politics research is to formalize and validate the decades of political knowledge generated in marginalized populations. This amplifies their voices in the political science literature. Dawson's original conceptualization of linked fate and the black utility heuristic exemplified this approach. The revolution he started remains unfinished.

\section{Conclusion}

We have proposed more expansive theoretical and methodological approaches for studying linked fate by returning to the foundations of the concept. First, serious pitfalls arise when researchers examine linked fate in individuals without investigating how this form of racial solidarity was set in motion at other levels. The black utility heuristic, Dawson's original theory underlying linked fate, tackles this problem by emphasizing both historical processes and social practices. Though these theoretical elements largely have been ignored in subsequent analyses of linked fate, they are crucial for explaining why and how a politicized racial solidarity emerged among African Africans. Second, the common practice of framing linked fate mostly as a direct outcome of racial discrimination may limit a deeper understanding of the role of ethnic elites in constructing this politically potent perception of groupness. Rather than simply assuming the connection between shared racial status and racial group consciousness, scholars should investigate how ethnic elites exercise their agency to shape the contours of racial group solidarity.

For the study of racial and ethnic politics to realize its full revolutionary potential in the American politics subfield, it is not enough to center racial minorities. Scholars also 
need to incorporate fully into their research the untapped knowledge of ethnic elites and the lived experiences of the groups they represent. Researchers studying the American carceral and welfare state from the racial perspective already have called for this kind of bottom-up-approach (Cohen and Luttig 2020; Weaver, Prowse, and Piston 2019; Michener, SoRelle, and Thurston 2020). A broad bottom-up view deepens our understanding not only of the political development of racial minority communities, but also how American democracy has functioned and faltered for those on its periphery. This perspective also illuminates the connections between racial and ethnic politics, public policy, and American political development. Researchers who study American political behavior should follow suit. The scholarship already has made a welcome turn to investigating the attitudes and behavior of racial and ethnic minorities. Yet behavioral research too often abstracts individuals from their lived experiences and history. Such contextual knowledge is crucial, however, for understanding the roots of racial minorities' political behavior and their will to exercise agency to overcome inequalities in power.

Finally, we recommend a mixed-methods approach that integrates research on elites and masses. Historical and ethnographic methods trace how ethnic elites and social practices build group solidarity. Surveys and experiments investigate the extent to which these elite-level decisions and social dynamics impact mass behavior. An integrative approach that combines these methods is essential for probing how group-centered attitudes like linked fate form. But this has to be a deliberate choice. Power determines which subjects are worthy of study, but also which methods are apt for social inquiry (Zuberi, Bonilla-Silva, et al. 2008; Emirbayer and Desmond 2015). Scholars have no control over how oral histories, meeting minutes, organizational newsletters, or ethnic newspaper articles are generated. Nor are we able to conduct in-depth interviews at numbers that would justify broad generalization. Most of these data sources, then, might fall short of conventional scientific standards (e.g., internal and external validity). Yet these unconventional data, at least in quantitativelyoriented American politics scholarship, could be the most theoretically and conceptually 
valid evidence for creating and expanding research programs devoted to minority populations. The insights gained from these methods can advance behavioral research with new ideas for survey and experimental design. Combining different methods and evidence is common in the comparative politics subfield, but less so in American politics. Researchers studying racial and ethnic politics in the U.S. can take the lead in reversing this trend if they further commit to grounding this field in the concrete realities of racially marginalized populations. The revolutionary potential of the decision to center these groups in our research demands no less. 


\section{References}

Austin, Sharon D Wright, Richard T Middleton, and Rachel Yon. 2012. "The effect of racial group consciousness on the political participation of African Americans and Black ethnics in Miami-Dade County, Florida." Political Research Quarterly 65 (3): 629-641.

Barreto, Matt A, and Dino Bozonelos. 2009. "Democrat, Republican, or none of the above? The role of religiosity in Muslim American party identification." Politics and Religion 2 (2): 200-229.

Barreto, Matt A, Sylvia Manzano, Ricardo Ramirez, and Kathy Rim. 2009. "Mobilization, participation, and solidaridad: Latino participation in the 2006 immigration protest rallies." Urban Affairs Review 44 (5): 736-764.

Barringer, Herbert R., Robert W. Gardner, and Michael J. Levin. 1993. Asians and pacific islanders in the United States. New York: Russell Sage Foundation.

Bobo, Lawrence D, and Camille Z Charles. 2009. "Race in the American mind: From the Moynihan report to the Obama candidacy." The Annals of the American Academy of Political and Social Science 621 (1): 243-259.

Brady, Henry E, and David Collier. 2010. Rethinking social inquiry: Diverse tools, shared standards. Rowman \& Littlefield Publishers.

Chong, Dennis. 2000. Rational lives: Norms and values in politics and society. University of Chicago Press.

Chong, Dennis, and Dukhong Kim. 2006. "The experiences and effects of economic status among racial and ethnic minorities." American Political Science Review 100 (3): 335-351.

Chong, Dennis, and Reuel Rogers. 2005. "Racial solidarity and political participation." Political Behavior 27 (4): 347-374. 
Cohen, Cathy J. 1999. The boundaries of blackness: AIDS and the breakdown of black politics. University of Chicago Press.

Cohen, Cathy J, and Matthew D Luttig. 2020. "Reconceptualizing political knowledge: Race, ethnicity, and carceral violence." Perspectives on Politics 18 (3): 805-818.

Colby, Sandra L, and Jennifer M Ortman. 2015. "Projections of the size and composition of the US population: 2014 to 2060." US Census Bureau.

Conover, Pamela Johnston. 1984. "The influence of group identifications on political perception and evaluation." The Journal of Politics 46 (3): 760-785.

- 1988. "The role of social groups in political thinking." British Journal of Political Science, 51-76.

Dawson, Michael C. 1994. Behind the mule: Race and class in African-American politics. Princeton University Press.

- 2001. Black visions: The roots of contemporary African-American political ideologies. University of Chicago Press.

Emirbayer, Mustafa, and Matthew Desmond. 2015. The racial order. University of Chicago Press.

Espiritu, Yen Le. 1993. Asian American panethnicity: Bridging institutions and identities. Temple University Press.

Gay, Claudine. 2004. "Putting race in context: Identifying the environmental determinants of Black racial attitudes." American Political Science Review, 547-562.

Gay, Claudine, Jennifer Hochschild, and Ariel White. 2016. "Americans' belief in linked fate: Does the measure capture the concept?" Journal of Race, Ethnicity and Politics 1 (1): 117-144. 
Gurin, Patricia, Shirley Hatchett, and James S Jackson. 1989. Hope and independence: Blacks' struggle in the two party system. Russell Sage.

Harris-Perry, Melissa V. 2004. Barbershops, bibles, and BET: everyday talk and Black political thought. Princeton University Press.

Hogg, Michael A, and Scott A Reid. 2006. "Social identity, self-categorization, and the communication of group norms." Communication theory 16 (1): 7-30.

Huddy, Leonie. 2013. "Group identity and political cohesion." In The Oxford handbook of political psychology, edited by David O Sears, Leonie Huddy, and Jervis Robert, 511-558. Oxford University Press.

Hurwitz, Jon, Mark Peffley, and Jeffery Mondak. 2015. "Linked fate and outgroup perceptions: Blacks, Latinos, and the US criminal justice system." Political Research Quarterly 68 (3): 505-520.

Jagmohan, Desmond. 2015. "Making bricks without straw: Booker T. Washington and the politics of the disenfranchised." PhD dissertation, Cornell University.

Jardina, Ashley, and Spencer Piston. 2019. "Racial prejudice, racial identity, and attitudes in political decision making." In Oxford Research Encyclopedia of Politics.

Junn, Jane, and Natalie Masuoka. 2008. "Asian American identity: Shared racial status and political context." Perspectives on Politics 6 (4): 729-740.

Katz, Elihu. 1957. "The two-step flow of communication: An up-to-date report on an hypothesis." Public Opinion Quarterly 21 (1): 61-78.

Kim, Claire Jean. 1999. "The racial triangulation of Asian Americans." Politics 63 Society 27 (1): 105-138.

—. 2018. "Are Asians the new Blacks?: Affirmative action, anti-blackness, and the 'sociometry' of race." Du Bois Review: Social Science Research on Race 15 (2): 217-244. 
Kim, Jae Yeon. 2020a. "How other minorities gained access: the War on Poverty and Asian American and Latino community organizing." Political Research Quarterly (December).

- 2020b. "Racism is not enough: Minority coalition building in San Francisco, Seattle, and Vancouver." Studies in American Political Development 34 (2): 195-215.

—. 2021. "Integrating human and machine coding to measure political issues in ethnic newspaper articles." Journal of Computational Social Science (January).

Kinder, Donald R, Lynn M Sanders, and Lynn M Sanders. 1996. Divided by color: Racial politics and democratic ideals. University of Chicago Press.

Lazarsfeld, Paul Felix, Bernard Berelson, and Hazel Gaudet. 1944. The people's choice: How the voter makes up his mind in a presidential campaign. Duell, Sloan \& Pearce.

Lee, Taeku. 2002. Mobilizing public opinion: Black insurgency and racial attitudes in the civil rights era. University of Chicago Press.

—. 2008. "Race, immigration, and the identity-to-politics link." Annual Review of Political Science 11:457-478.

Lenz, Gabriel S. 2013. Follow the leader?: how voters respond to politicians' policies and performance. University of Chicago Press.

Lien, Pei-te, M Margaret Conway, and Janelle Wong. 2003. "The Contours and Sources of Ethnic Identity Choices among Asian Americans." Social Science Quarterly 84 (2): $461-481$.

Lu, Fan, and Bradford Jones. 2019. "Effects of belief versus experiential discrimination on race-based linked fate." Politics, Groups, and Identities 7 (3): 615-624.

Lupia, Arthur. 1994. "Shortcuts versus encyclopedias: Information and voting behavior in California insurance reform elections." American Political Science Review, 63-76. 
Masuoka, Natalie. 2006. "Together they become one: Examining the predictors of panethnic group consciousness among Asian Americans and Latinos." Social Science Quarterly 87 (5): 993-1011.

Masuoka, Natalie, and Jane Junn. 2013. The politics of belonging: Race, public opinion, and immigration. University of Chicago Press.

McClain, Paula D, Jessica D Johnson Carew, Eugene Walton Jr, and Candis S Watts. 2009. "Group membership, group identity, and group consciousness: Measures of racial identity in American politics?" Annual Review of Political Science 12:471-485.

McConnaughy, Corrine M, Ismail K White, David L Leal, and Jason P Casellas. 2010. "A Latino on the ballot: Explaining coethnic voting among Latinos and the response of White Americans." The Journal of Politics 72 (4): 1199-1211.

Michener, Jamila, Mallory SoRelle, and Chloe Thurston. 2020. "From the margins to the center: A bottom-up approach to welfare state scholarship." Perspectives on Politics, $1-16$.

Mora, G Cristina. 2014. Making Hispanics: How activists, bureaucrats, and media constructed a new American. University of Chicago Press.

Okamoto, Dina G. 2014. Redefining race: Asian American panethnicity and shifting ethnic boundaries. Russell Sage Foundation.

Padilla, Felix M. 1985. Latino ethnic consciousness: The case of Mexican Americans and Puerto Ricans in Chicago. University of Notre Dame Press.

Philpot, Tasha S, and Hanes Walton Jr. 2007. "One of our own: Black female candidates and the voters who support them." American Journal of Political Science 51 (1): 49-62. 
Pierson, Paul. 2003. "Big, slow-moving, and ... invisible: Macrosocial processes in the study of comparative politics." In Comparative Historical Analysis in the Social Sciences, edited by James Mahoney and Dietrich Rueschemeyer, 177-207. Cambridge University Press.

Pinderhughes, Dianne Marie. 1987. Race and ethnicity in Chicago politics: A reexamination of pluralist theory. University of Illinois Press.

Popkin, Samuel L. 1993. Information shortcuts and the reasoning voter. University of Michigan Press.

Rogers, Reuel R. 2006. Afro-Caribbean immigrants and the politics of incorporation: Ethnicity, exception, or exit. Cambridge University Press.

- 2018. "Black come-outers and the counterpublic: how suburbanization is diversifying black attitudes." In Black Politics in Transition: Immigration, Suburbanization, and Gentrification, edited by Candis Watts Smith and Christina M Greer. Routledge.

Rosenbloom, Susan Rakosi, and Niobe Way. 2004. "Experiences of discrimination among African American, Asian American, and Latino adolescents in an urban high school.” Youth 8 Society 35 (4): 420-451.

Rosenthal, Aaron. 2020. "Submerged for some? Government visibility, race, and American political trust." Perspectives on Politics, 1-17.

Sanchez, Gabriel, Natalie Masuoka, and Brooke Abrams. 2019. "Revisiting the brown-utility heuristic: a comparison of Latino linked fate in 2006 and 2016." Politics, Groups, and Identities 7 (3): 673-683.

Sanchez, Gabriel R. 2008. "Latino group consciousness and perceptions of commonality with African Americans." Social Science Quarterly 89 (2): 428-444. 
Sanchez, Gabriel R, and Natalie Masuoka. 2010. "Brown-utility heuristic? The presence and contributing factors of Latino linked fate." Hispanic Journal of Behavioral Sciences 32 (4): $519-531$.

Sanchez, Gabriel R, and Edward D Vargas. 2016. "Taking a closer look at group identity: The link between theory and measurement of group consciousness and linked fate." Political Research Quarterly 69 (1): 160-174.

Schuman, Howard, Charlotte Steeh, Lawrence Bobo, et al. 1985. Racial attitudes in America: Trends and interpretations. Harvard University Press.

Seawright, Jason. 2016. Multi-method social science: Combining qualitative and quantitative tools. Cambridge University Press.

Sen, Maya, and Omar Wasow. 2016. "Race as a bundle of sticks: Designs that estimate effects of seemingly immutable characteristics." Annual Review of Political Science 19:499-522.

Shelby, Tommie. 2005. We who are dark: The philosophical foundations of black solidarity. Harvard University Press.

Shingles, Richard D. 1981. "Black consciousness and political participation: The missing link." American Political Science Review, 76-91.

Sidanius, Jim, Felicia Pratto, and Lawrence Bobo. 1996. "Racism, conservatism, affirmative action, and intellectual sophistication: A matter of principled conservatism or group dominance?" Journal of Personality and Social Psychology 70 (3): 476.

Sniderman, Paul M, and Thomas Leonard Piazza. 1993. The scar of race. Harvard University Press.

Stout, Christopher T, Kelsy Kretschmer, and Leah Ruppanner. 2017. "Gender linked fate, race/ethnicity, and the marriage gap in American politics." Political Research Quarterly $70(3): 509-522$. 
Tate, Katherine. 2010. What's going on?: Political incorporation and the transformation of Black public opinion. Georgetown University Press.

Vargas, Edward D, Gabriel R Sanchez, and Juan A Valdez. 2017. "Immigration policies and group identity: How immigrant laws affect linked fate among US Latino populations." Journal of Race, Ethnicity and Politics 2 (1): 35-62.

Verba, Sidney, and Norman H Nie. 1972. Participation in America: Political democracy and social equality. Harper / Row.

Verkuyten, Maykel. 2017. "Supporting the democratic political organisation of Muslim immigrants: The perspective of Muslims in the Netherlands and Germany." Journal of Ethnic and Migration Studies 43 (1): 137-155.

Watts Smith, Candis. 2013. "Ethnicity and the role of group consciousness: a comparison between African Americans and Black immigrants." Politics, Groups, and Identities 1 (2): 199-220.

Weaver, Vesla, Gwen Prowse, and Spencer Piston. 2019. "Too much knowledge, too little power: An assessment of political knowledge in highly policed communities." The Journal of Politics 81 (3): 1153-1166.

White, Ismail K. 2007. "When race matters and when it doesn't: Racial group differences in response to racial cues." American Political Science Review 101 (2): 339-354.

White, Ismail K, and Chryl N Laird. 2020. Steadfast democrats: How social forces shape Black political behavior. Princeton University Press.

White, Ismail K, Chryl N Laird, and Troy D Allen. 2014. "Selling out?: the politics of navigating conflicts between racial group interest and self-interest." American Political Science Review 108 (4): 783-800.

Zaller, John R. 1992. The nature and origins of mass opinion. Cambridge university press. 
Zuberi, Tukufu, Eduardo Bonilla-Silva, et al. 2008. White logic, white methods: Racism and methodology. Rowman \& Littlefield Publishers. 


\section{Online Appendix}

\section{Appendix A Additional descriptive data}

Publication trend on linked fate sorted by research subjects

\begin{tabular}{lllll} 
Research subjects & Asian Americans & Black immigrants & Others \\
\cline { 2 - 3 } & Black & Latino & Whites
\end{tabular}

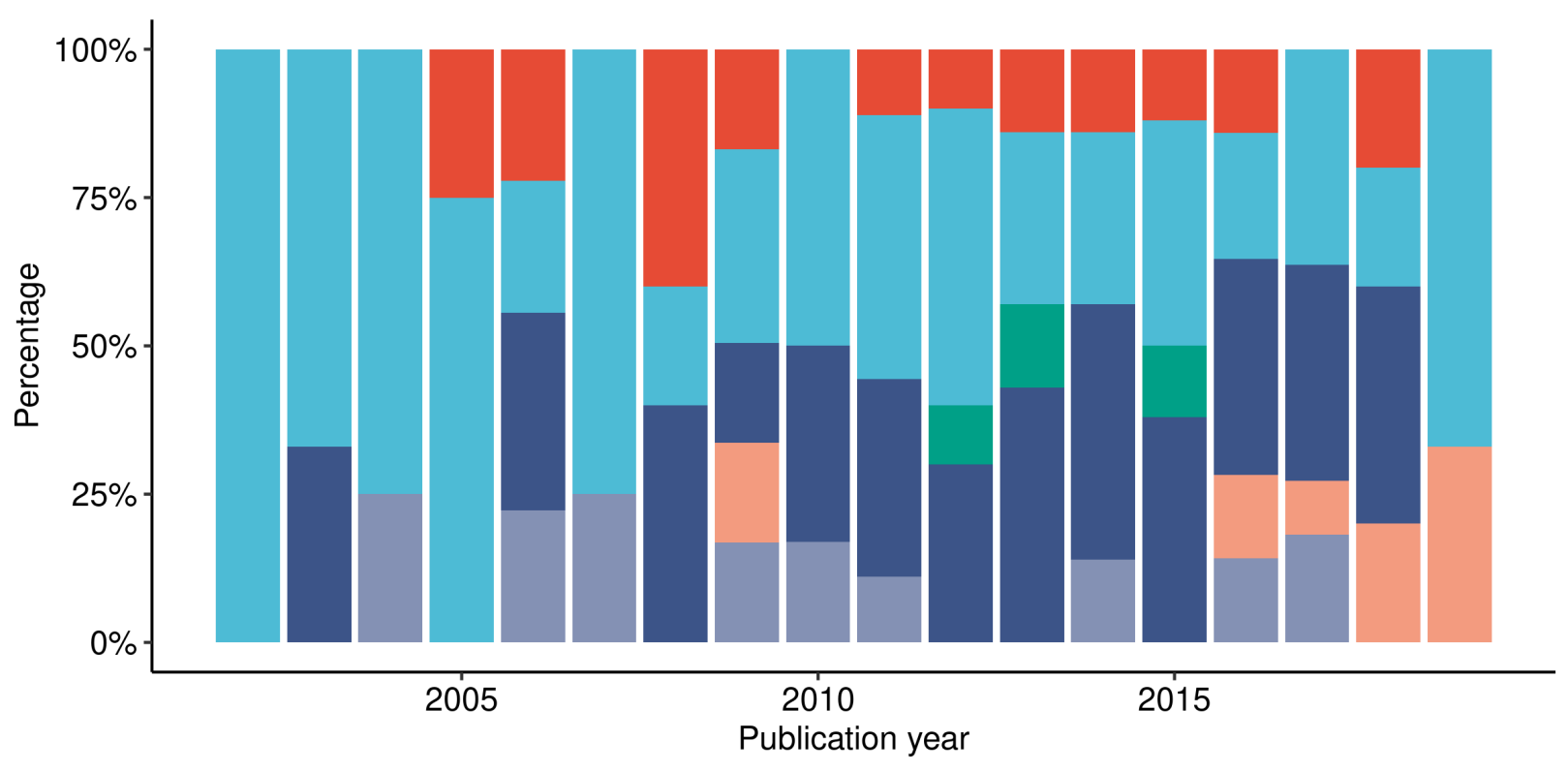

Figure A.1: Publication trend on linked fate sorted by research subjects 
Publication trend by data type

Data types Experiment Qualitative Survey

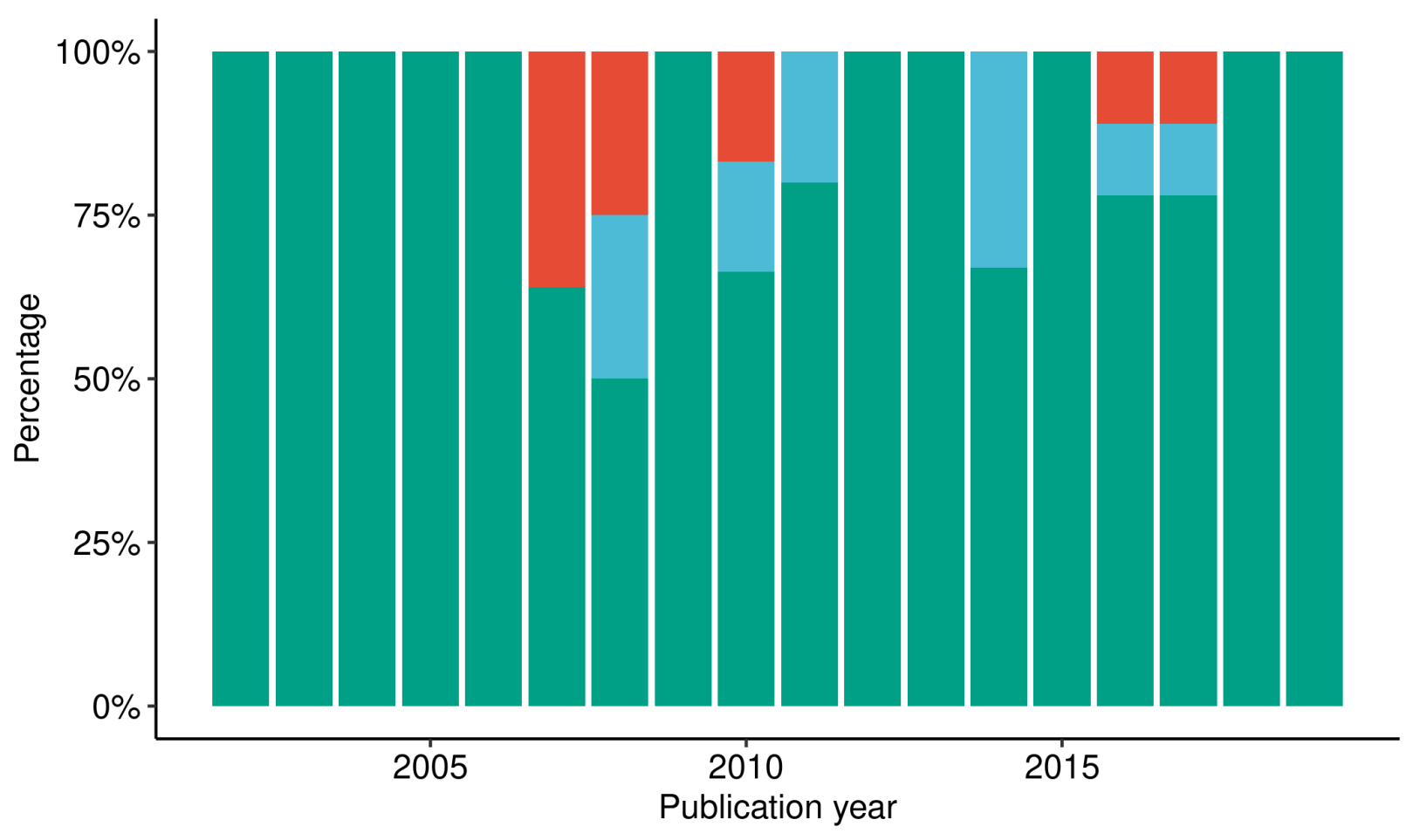

Figure A.2: Publication trend by data type 


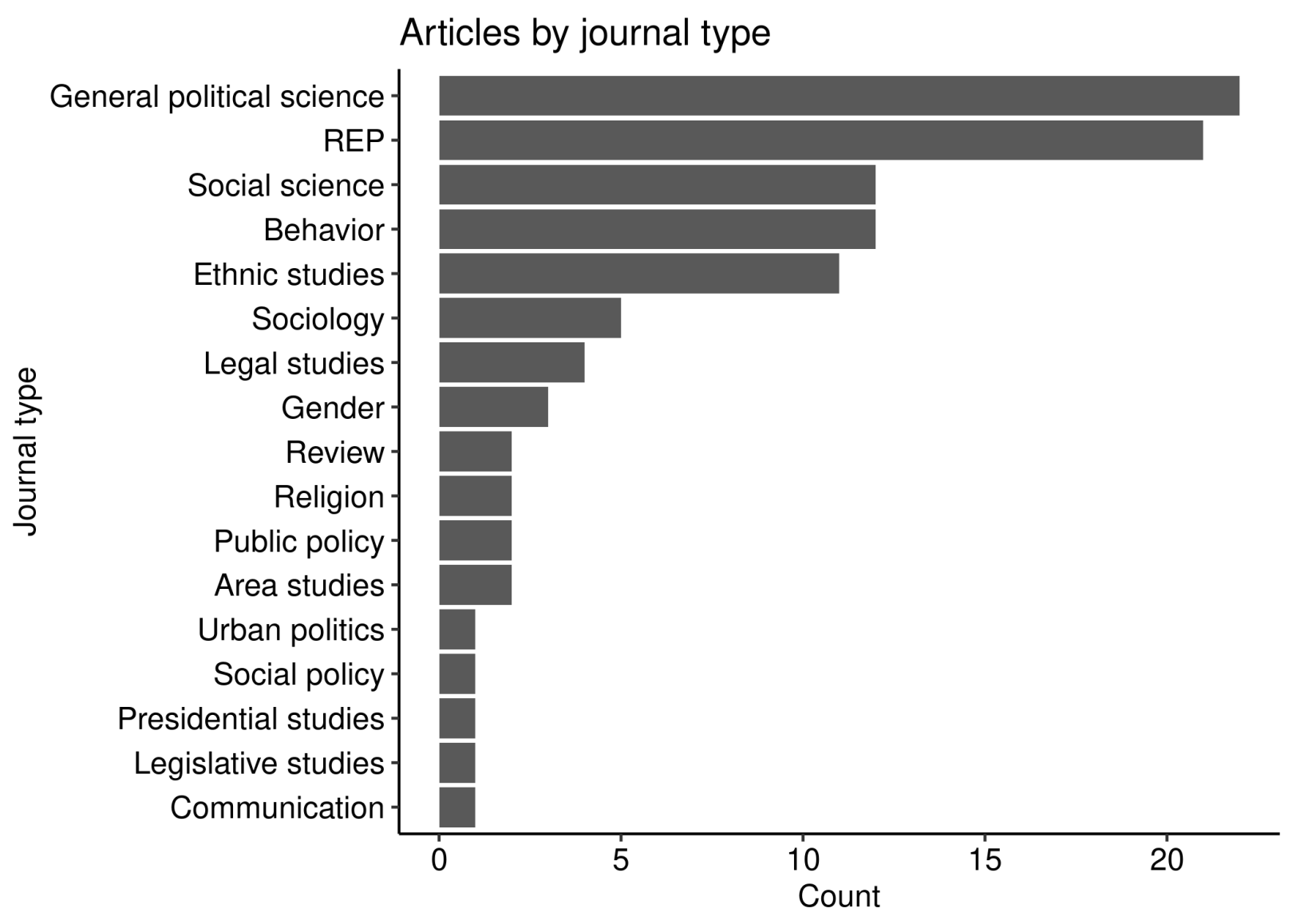

Figure A.3: Articles by journal type 